\title{
Numerical modelling of three-dimensional masonry arch bridge structures
}

\author{
Stanyslav Grosman MSc, DIC, PhD \\ Research Associate, Department of Civil and Environmental \\ Engineering, Imperial College London, London, UK \\ (Orcid:0000-0003-4474-7838) \\ Alejandro Barrero Bilbao BEng, MSC, DIC, PhD \\ Research Associate, Department of Civil and Environmental Engineering, \\ Imperial College London, London, UK \\ Lorenzo Macorini MEng, PhD \\ Reader, Department of Civil and Environmental Engineering, Imperial \\ College London, London, UK (Orcid:0000-0002-0358-1432) \\ (corresponding author: I.macorini@imperial.ac.uk)
}

Bassam A. Izzuddin BEng, MSc, DIC, PhD, FIStructE

Professor, Department of Civil and Environmental Engineering, Imperial College London, London, UK (Orcid:0000-0001-5746-463X)

A substantial part of the underline bridges that belong to the asset collection of the main railway and roadway infrastructure operators in the UK and Europe have the structural shape of arches, typically constructed from brick/stone masonry. Current assessment methods, which consider two-dimensional descriptions, do not enable an accurate representation of the typical three-dimensional response, and often they do not provide realistic predictions of the development of damage in the various components including arches, piers and spandrel walls. In this paper, two alternative 3D finite-element modelling strategies offering different balance between sophistication and computational efficiency are presented. The first approach is based on a detailed mesoscale masonry model, where a distinction is made between constituents allowing for an accurate description of masonry under various bond conditions. The second approach is based on a macroscale representation, where a homogeneous description of masonry is assumed. In both approaches, the interactions between the spandrel walls and the backfill and arches, as well as between the backfill and the arches' extrados, are explicitly incorporated into the model. This interaction effect is investigated with the two approaches, and comparisons are made between the respective simulations to illustrate the relative benefits of mesoscale and macroscale modelling.

\section{Notation}

$c_{\mathrm{f}}$

$c_{\mathrm{i}}$

$E_{\mathrm{b}}$

$E_{\mathrm{f}}$

$E_{\mathrm{m}}$

$f_{\mathrm{cm}}$

$f_{\mathrm{ci}}$

$f_{\mathrm{ti}}$

$f_{\mathrm{tm}}$

$G_{\mathrm{fm}}$

$G_{\mathrm{si}}$

$G_{\mathrm{ti}}$

$k_{\mathrm{n}}$

$\begin{array}{ll}\varphi_{\mathrm{f}} & \begin{array}{l}\text { internal friction angle (rad) of the backfill } \\ \text { material }\end{array} \\ \varphi_{\mathrm{i}} & \begin{array}{l}\text { internal friction angle (rad) of the non-linear } \\ \text { interface }\end{array} \\ \psi_{\mathrm{f}} & \text { dilatancy angle (rad) of the backfill material } \\ \psi_{\mathrm{i}} & \text { dilatancy angle (rad) of the non-linear interface } \\ \psi_{\mathrm{m}} & \text { dilatancy angle (rad) of the macroscale masonry }\end{array}$

\section{Introduction}

Masonry arch bridges are heterogeneous structural systems. The nature of their response is strictly three-dimensional (3D); it is dictated by the interaction between a variety of structural and non-structural elements spatially interconnected which gives rise to composite effects and complex failure modes.

The main components of stone and brick-masonry single-span arch bridges (Figure 1) include the arch barrel with different shapes (e.g. segmental, parabolic, elliptical), the backfill, the spandrel and wing walls, the abutments and the piers in the case of multi-span structures. 


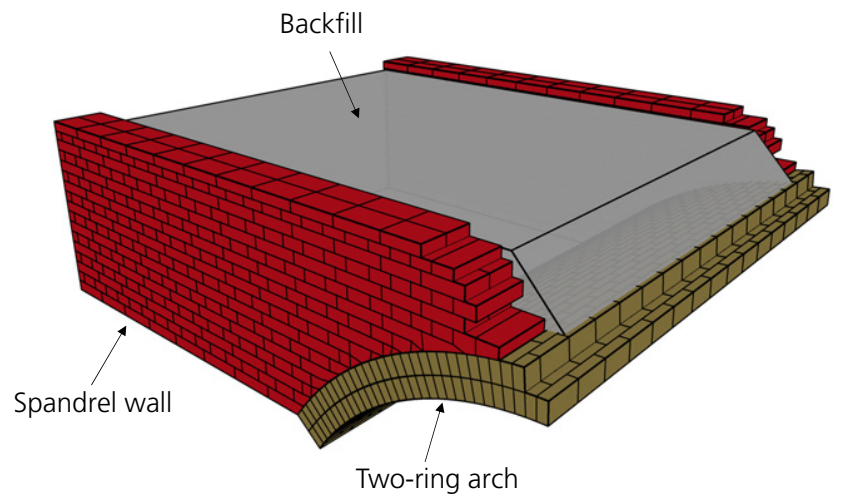

Figure 1. Main elements of a single-span masonry bridge

In brick-masonry bridges, brickwork arch barrels may consist of several concentric rings. The spatial arrangement of the bricks with the mortar layers inside the barrel generates various bond types, which in turn influence the potential distribution of cracks on loading. Layers of compacted backfill are normally placed over the arch barrel to facilitate the spread of load. Providing confinement to the backfill along the entire arch bridge up to the abutments are the spandrel walls. They are placed at the edges of the arch and enable the retaining of a levelled top surface by the fill bulk. Spandrel walls are usually assumed to restrain the upwards deflection, and contribute, alongside the arch barrel, to create a stiff load path that hinders the mobilising of passive soil pressure.

The study of failure mechanisms in whole bridges has necessitated field tests on existing assets, reported for example in Page (1995). In these tests, vertical loading led to distinct failure types, depending on the arch geometry and material properties of both masonry and backfill. Apart from the successive hinge formation characteristic of stand-alone arch barrels, which becomes less apparent when mobilising the spandrels and the backfill as well, crushing of masonry and falling out of bricks were also observed. When the arch barrel is formed by several superimposed rings, failure may also be induced by ring separation. Laboratory tests reported in Melbourne and Gilbert (1995) corroborate that this usually entails a reduction in the overall load-carrying capacity. The arch-fill interaction - that is, the mobilising of the soil pressure and its effect on the arch deformation during its transition towards a mechanism, has also been subject to extensive research. Melbourne and Walker (1990), Gilbert et al. (2006) and Augusthus-Nelson et al. (2018), among others, have experimentally confirmed the incidence of the soil pressure by observing that applying load on the backfill mobilises active and passive pressure fronts. These tend to occur at opposite sides of the arch and have destabilising and stabilising effects on the arch deformation, respectively. In the tests, four-hinge mechanisms were observed at failure, which were facilitated also by the masonry bond of the arches, as in AugusthusNelson et al. (2018) where the presence of headers prevented ring separation.

Specific laboratory tests (Melbourne et al., 1997; Peng et al., 1997) to measure the contribution of the interaction between arch barrels, spandrels and backfill to the bridge strength have shown that the composite action has a substantial effect on capacity, although the activated failure mechanism becomes more complex and less intuitive.

The pressing need of predicting the load-carrying capacity of the large population of masonry arch bridges in the UK and worldwide has led to the development of assessment methods and modelling strategies for these complex structural systems, whose level of complexity and potential accuracy has grown in recent years due to advances in computational mechanics and the availability of superior computing resources.

In the following, previous assessment methods and numerical models for masonry arch bridges are briefly presented, focusing on their ability to represent typical 3D response characteristics. Then, 3D non-linear modelling strategies based on macro- and mesoscale descriptions for masonry are presented and used to analyse the behaviour up to collapse of a singlespan masonry bridge. The obtained results shed some light on the potential, benefits and limitations of the proposed 3D models for masonry arch bridges.

\section{Assessment methods and modelling strategies for masonry arch bridges}

In the past decades, different assessment methods and numerical modelling strategies for masonry arch bridges have been developed. In the main, three different approaches can be used in practical assessment and for more accurate predictions: semi-empirical approaches, equilibrium-based methods and solid mechanics computational methods.

\subsection{Semi-empirical approaches}

A semi-empirical approach for the assessment of masonry arch bridges emerged from early work by Pippard (1948) and Pippard and Chitty (1951) and culminated in the development of the well-established and widespread MEXE method, which is still the paradigm of this type of methodology. The empirical component of this method comes from a series of assumptions stemming from experimental studies which are in turn combined with linear elasticity. They include the shape of the arch, which is assumed as parabolic, a fixed span-to-rise ratio of 4 , 
pinned abutments, the load position at the arch crown and prescribed stress limits for the masonry in tension $(0.7 \mathrm{MPa})$ and compression $(1.4 \mathrm{MPa})$. Over time, the original method has been subject to revisions in the definition of a series of factors associated with geometric or material characteristics and requiring engineering judgement for their determination. In any case, the compact set of assumptions, alongside a series of modification and axle factors are used to transform a provisional axle load into a maximum vehicle weight, constitute the basis of an assessment method that has been widely used over a significant timespan. All these alterations from the original definition, however, have extended the method probably beyond the scope anticipated by its authors, which has led to recommendations of caution when resorting to it. In general, the MEXE method cannot accommodate 3D effects, given its simplicity of formulation, originally aimed at facilitating its quick application.

\subsection{Equilibrium-based methods}

Alternatively, more refined assessment strategies stem from the equilibrium-based methodology embedding the plastic analysis theorems. Such strategies resort to the kinematic theorem providing an upper bound for the load-carrying capacity as a result of the formation of a sufficient number of plastic hinges to turn the statically indeterminate arch of a masonry bridge into a mechanism (Livesley, 1978). Typically, the assumptions involved in the mechanism method correspond to the classical ones proposed by Heyman (1982): (a) the arch has no tensile strength, $(b)$ the arch has unbounded compressive strength and (c) sliding between blocks is prevented. Since the application of the kinematic theorem of plasticity leads to an upper bound of the load-carrying capacity, an optimisation problem needs to be solved in order to find the most unfavourable configuration of plastic hinges. This requires a thorough consideration of all potential failure mechanisms, which readily calls for computer implementation of solving procedures, as in Crisfield and Packham (1987) and in Gilbert and Melbourne (1994). As the optimisation programmes become more sophisticated, they incorporate progressively more refined strategies allowing for ring sliding and capturing the arch-fill interaction and its impact on the load-carrying capacity (Callaway et al., 2012). In the limit, further refinements have maintained the principles of the method with regards to the constitutive characterisation of materials and the global solution procedure, but these have shifted the implementation framework to that of one (1D)- or two-dimensional (2D) finite-element (FE) analysis, as in Cavicchi and Gambarotta (2007). In any case, most of limit analysis assessment tools are $2 \mathrm{D}$ in nature, and thus far only a few attempts have been made to apply limit analysis procedures to investigate 3D effects in masonry arch bridges at failure, as in Milani and Lourenço (2012).

\subsection{Solid mechanics computational methods}

Although mechanism methods are easy to implement and apply, which may be suitable depending on the required level of assessment accuracy and availability of computational resources, advanced computational tools are needed to adequately capture the onset and propagation of damage in the brickwork up to collapse. However, the accuracy of sophisticated numerical predictions strongly depends on the availability of critical model material parameters which may not be readily available when assessing existing structures.

The paradigm of this modelling methodology is mainly based on the FE method. The advent of high-performance computing enabled utilisation of the higher dimension (3D) FEs. The increase in dimensionality allows for a more realistic representation of the structure, but it also entails a series of requirements related to the material modelling and the analysis input parameters, the calibration of which has to be carefully undertaken.

In principle, the most straightforward method of modelling the arch barrel consists of representing it by beam or truss (1D) elements, as in Towler and Sawko (1982) or Choo et al. (1990) for a single-span arch. A multi-span bridge response can also be successfully modelled with $1 \mathrm{D}$ elements, as in Brencich and De Francesco (2004), where specific material assumptions regarding the masonry response under compression (elastic -perfectly plastic) and tension (no resistance) are made. Models based on 1D elements typically lack an explicit representation of the contribution of spandrel walls or the arch -fill interaction. Crisfield (1985) addressed this by resorting to non-linear spring elements to represent soil pressure. Later, De Santis and de Felice (2014) used non-linear truss elements to represent not just the backfill but the backing and the abutments.

Despite this versatile extension of the scope of applicability, this modelling strategy is still inherently incapable of accurately representing $3 \mathrm{D}$ effects. It is not intuitive to translate $1 \mathrm{D}$ inelastic results into observed local deterioration phenomena.

Extending the description of the bridge geometry using 2D element models improves the accuracy of the representation. Several works have explicitly modelled masonry and backfill by way of elasto-plastic elements to evaluate the load-carrying capacity and the structural response of bridges - for example, Audenaert et al. (2008), Gago et al. (2011) or Chandra Kishen et al. (2013).

A further improvement on the description of the bridge geometry leads to the full 3D FE framework. As with the 2D case, and in a more accentuated manner, geometry generation and processing time are key factors that have typically 
prevented their application in assessment practice. With a full spatial geometric definition of the model, shortcomings of lower dimensional representations can be naturally overcome. The spandrels, the backfill, the piers and the abutments can be explicitly represented with potentially separate material properties. This facilitates capturing transverse effects (across the bridge width) that may cause longitudinal cracking in the arch intrados, in turn reducing load-carrying capacity overestimations, as shown in Fanning et al. (2001). Continuum-based approaches like the ones referenced hitherto rely on a macroscale description of the elements. That is, masonry is considered a single homogeneous and isotropic continuum where non-linear effects are captured in a 'smeared' fashion. This has computational benefits but is a simplification of the real heterogeneity arising from the mixture of bricks and mortar. Garrity and Toropova (2001) modelled a single-span highway bridge following this macro-scale approach and highlighted some potential limitations regarding the unsuitability of the material models in commercial software packages and the difficulty in retrieving reliable material parameters.

A consolidated alternative to the paradigm of FEs is that of discrete-element analysis in its various forms. Particle models, originally stemming from the analysis of granular materials, have been adapted to masonry, in particular for the modelling of the backfill and its interaction with the arch barrel, as discussed in Thavalingam et al. (2001). The representation of the material as amalgamated spheres with non-linear contact laws necessitates an explicit integration algorithm, which may lead to a significant computational cost when scaling up the model, particularly when allowing the particles that form a masonry unit to have breakable bonds. Furthermore, if the backfill is not granular, this type of modelling becomes unsuitable. The generalisation of this method to three dimensions is not straightforward from a computational perspective and the representation of structural elements by clustered particles makes the interpretation of model outcomes in relation to observed local phenomena less intuitive.

Further, 3D approaches to the application of the discrete or distinct element method (Hart et al., 1988) on masonry arches as in Forgács et al. (2017) and masonry bridges as in Pulatsu et al. (2019) entail a greater sophistication in the representation of the contact conditions and the deformability of the blocks. However, since at its core the distinct element method still involves an explicit integration algorithm, such approaches also have to comply with computational requirements to ensure numerical stability that may become excessive for largescale specimens. A recent discrete macro-element method (Caddemi et al., 2019) introduces computational efficiency benefits, though the relatively large size of macro-elements may pose particular challenges, especially in relation to identifying local damage associated with the serviceability limit state.

\section{3D non-linear macro- and mesoscale modelling for masonry arch bridges}

Modelling strategies with 3D solid and 2D interface elements have been recently developed at Imperial College London and implemented in ADAPTIC (Izzuddin, 1991) for 3D FE analysis of masonry arch bridges allowing for material and geometric non-linearity. Material non-linearity in masonry is taken into account by employing mesoscale or macroscale models. The backfill is modelled as a homogeneous and isotropic continuum using a robust and well-established nonassociated plastic model with a modified Drucker-Prager yield criterion to represent its cohesive and frictional nature, as discussed in Tubaldi et al. (2018). The interaction between arch barrel, backfill and spandrel walls is modelled employing non-linear interface elements enabling plastic separations and sliding. Geometric non-linearity is considered by using a corotational approach for interface elements (Macorini and Izzuddin, 2011) and Green strains for solid elements.

\subsection{Non-linear descriptions for masonry material}

\subsubsection{Mesoscale model}

In the mesoscale description for masonry, the masonry material is modelled based on separate representations for brick units and mortar joints. More specifically, as elaborated in Macorini and Izzuddin (2011), elastic quadratic solid elements are used to describe units and non-linear quadratic interface elements to represent mortar joints and potential fracture surfaces within bricks. The material description for non-linear interfaces is based on a cohesive-frictional constitutive model (Minga et al., 2018a), providing computationally robust and efficient solutions of the local non-linear problem. A multi-surface yield criterion in the stress domain is adopted, while the degradation of strength and stiffness is captured through the evolution of an anisotropic damage tensor, which is coupled with the plastic work. Importantly, mesoscale material parameters can be obtained by small-scale tests on individual components as in CUR (1994) and also by way of inverse analysis based on low-invasive in situ experiments (Chisari et al., 2018).

The adopted masonry mesoscale strategy has been recently applied to represent single- and multi-ring arches in isolation (Zhang et al., 2016, 2018a) and to investigate the response of single-span and multi-span bridges (Tubaldi et al., 2018, 2020a, 2020b; Zhang et al., 2018b). Efficient mesoscale strip bridge models allowing for arch-backfill interaction were also employed in extensive sensitivity analysis (Tubaldi et al., 2020a). It was established that the load capacity of masonry arch bridges is significantly affected by the cohesion of the backfill, whereas the most critical masonry material characteristic is the friction angle of mortar joints followed by cohesion and tensile strength. Similar models were employed 
in further parametric simulations to investigate the influence of main geometric parameters of arches and piers in multispan bridges (Tubaldi et al., 2020b). It was found that increasing the pier slenderness results in a significant reduction of the bridge capacity, whereas increasing the rise to span ratio of the arch increases the collapse load. In general, in mesoscale models the separate description of the masonry constituents enables also a realistic representation of complex arch geometries (e.g. skew arches) capturing of radial cracking, ring separation and complex $3 \mathrm{D}$ cracks, though at a greater computational cost as compared to macroscale modelling.
In previous 3D models for masonry bridges (Tubaldi et al., 2018; Zhang et al., 2018b) only masonry arches were modelled employing a mesoscale representation, while spandrel walls were dscribed by a more efficient macroscale approach. In this study for the first time, the proposed mesoscale description is used for both arches and spandrel walls enabling the representation of realistic cracks in all the masonry parts.

\subsubsection{Macroscale model}

The material description within this framework is based on a constitutive model combining the concepts of plasticity and damage assuming masonry as a single constituent. Such a

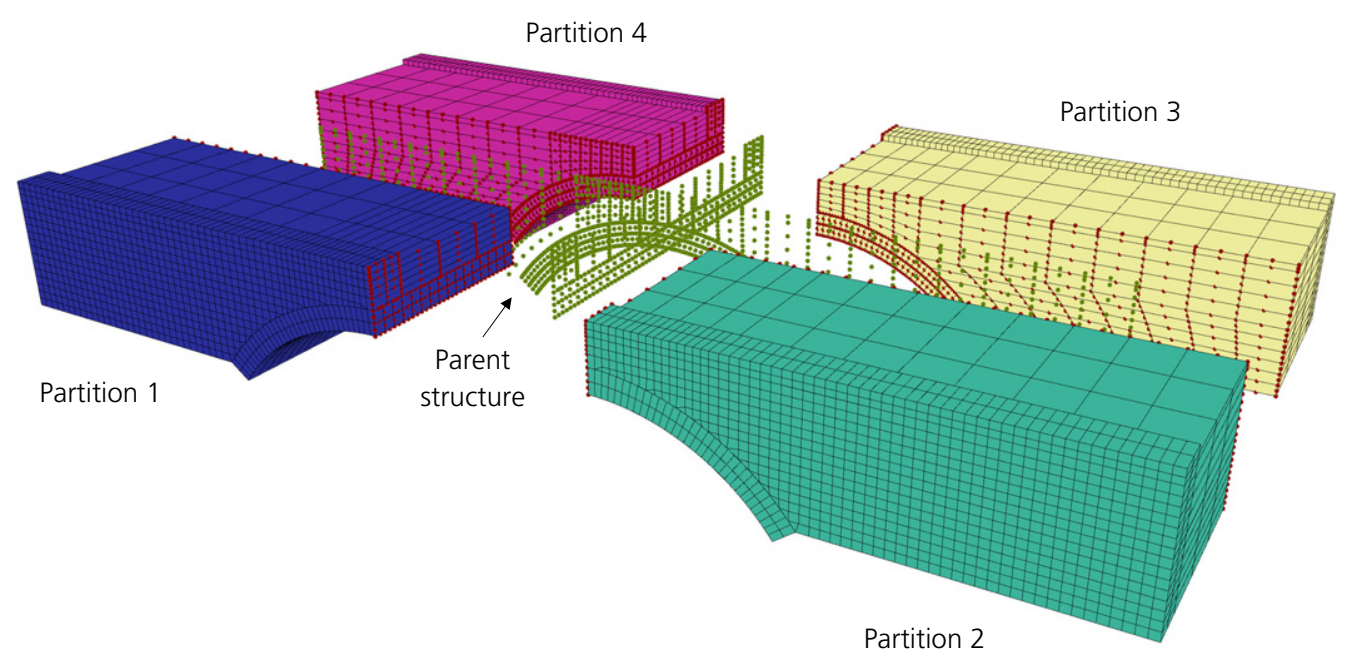

Figure 2. 3D FE model with four partitions for a single-span masonry bridge

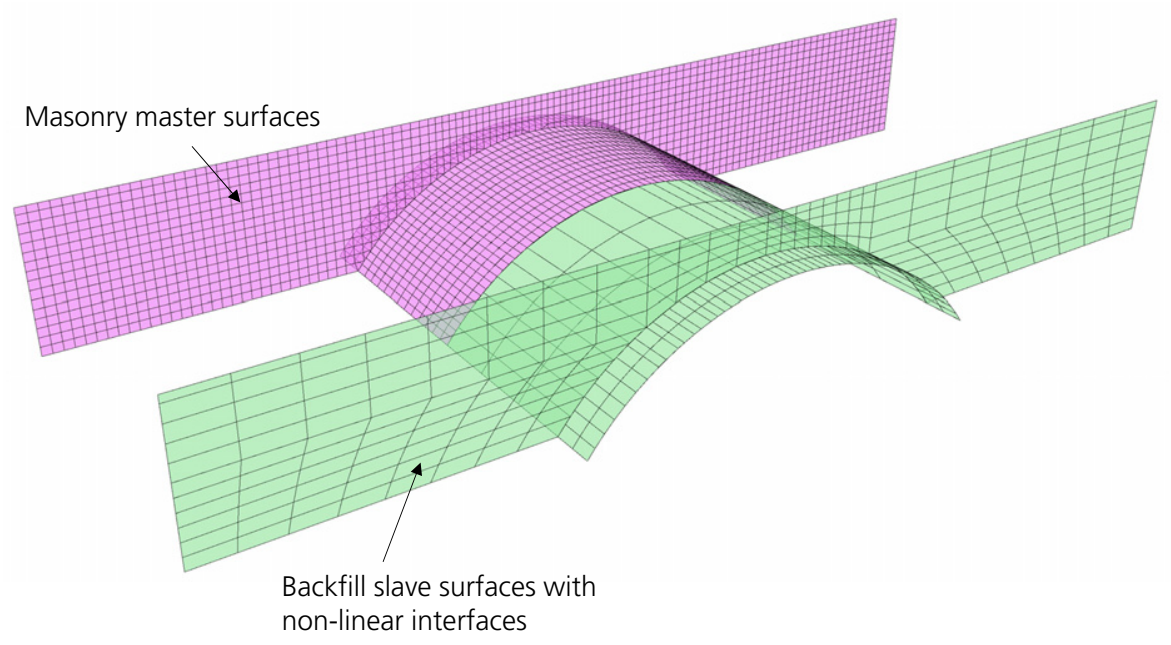

Figure 3. Masonry and backfill surfaces at the physical interfaces between the different subdomains connected by way of mesh tying 


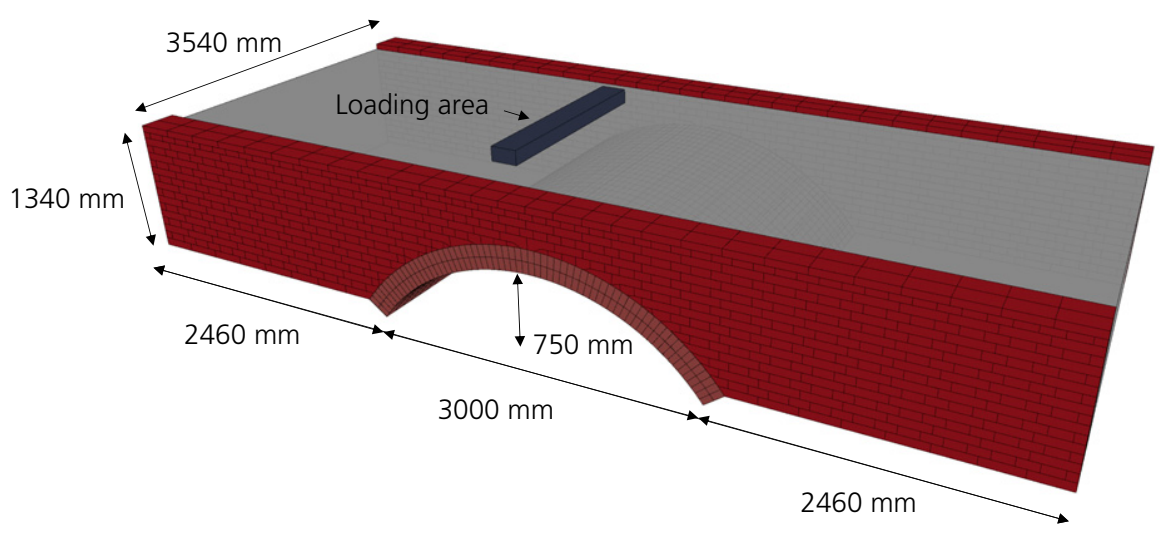

Figure 4. Masonry bridge specimen (source: Bridge 3-3, Melbourne and Gilbert, 1995)

combination has proven to be effective in capturing both irreversible deformations and the deterioration of stiffness in quasi-brittle materials. The details of the underlying formulation and its implementation in ADAPTIC can be found in Lee and Fenves (1998) and Chisari et al. (2020), respectively. As noted before, these constitutive models are employed for a homogenised continuum representation of the masonry in arch bridges, hence appropriate interpretation is needed to relate the results to the nature of the real material, comprising distinct constituents. In general, the reduction of the modelled material to a single constituent guarantees computational benefits, but it requires calibration of the material parameters based on physical tests on large components or the use of homogenisation techniques. The model material parameters of standard non-linear continuum descriptions can also be calibrated by employing multi-scale calibration strategies as in Chisari et al. (2020), which require information from physical tests at the level of the masonry constituents.

\subsection{Partitioned modelling and mesh tying}

Detailed 3D modelling of complex structural systems as realistic masonry arch bridges entails the use of a large number of degrees of freedom (DOFs), which renders the solution of the non-linear problem impractical, especially when using standard computation resources. To overcome such inherent drawback and improve computational efficiency, a domain decomposition approach earlier developed at Imperial College (Jokhio and Izzuddin, 2015) is utilised. According to this strategy, a large structure is divided into partitions (Figure 2) corresponding to subdomains of the original structure and a 'parent structure', which is composed of dual super-elements. Each super-element consists of the boundary nodes of an individual partition and accounts for the two-way communication of the subdomain with the parent structure, which allows the parallelisation of the analysis. In earlier research, such computational strategy was effectively used in mesoscale simulations of masonry components (Macorini and Izzuddin, 2013) including arches (Zhang et al., 2016) and bridges (Tubaldi et al., 2018; Zhang et al., 2018b) leading to a significant reduction of the computing time, which can be further reduced with the adoption of mixed-dimensional coupling (Izzuddin and Jokhio, 2017) albeit with minor consequent reduction in accuracy (Zhang et al., 2016).

To enable an independent selection of the mesh characteristics for the different parts of a masonry bridge model, improving further computational efficiency, a mesh tying strategy (Minga et al., 2018b) based on the mortar method is employed. At the

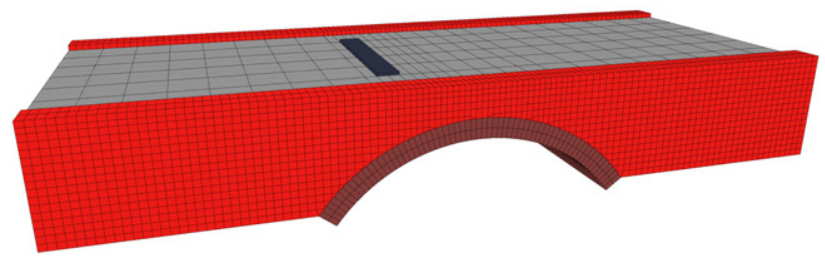

Mesoscale model

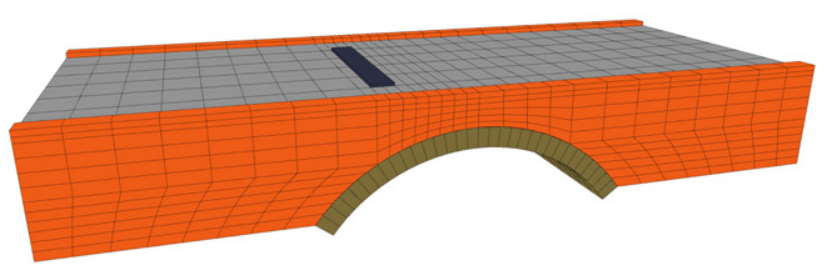

Macroscale model

Figure 5. 3D modelling strategies for the single-span specimen Bridge 3-3 
Table 1. Number of elements and DOFs used to represent the different components in the mesoscale and macroscale models

\begin{tabular}{lrrrr} 
& Arch & Lateral walls & Backfill & Physical interfaces \\
\hline Mesoscale model & & & & \\
20-noded solid elements & 4096 & 5936 & 1416 & 0 \\
15-noded solid elements & 0 & 96 & 0 & 0 \\
16-noded interface elements & 1048 & 468 & 0 & 0 \\
12-noded interface elements & 0 & 360480 & 21855 & 19584 \\
DOFs & 245760 & 528 & 1416 & 0 \\
Macroscale model & 512 & 0 & 0 & 0 \\
20-noded solid elements & 0 & 0 & 0 & 0 \\
15-noded solid elements & 0 & 0 & 21855 & 0 \\
16-noded interface elements & 0 & 12486 & 0
\end{tabular}

Table 2. Mesoscale material properties

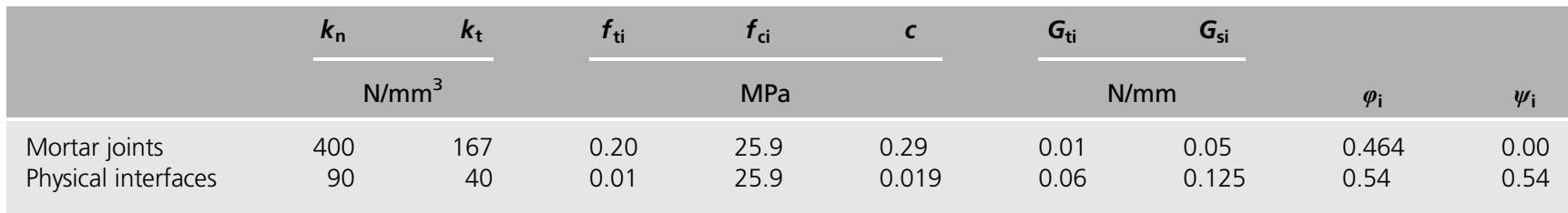

physical interfaces between the bridge components (e.g. arch, lateral walls and backfill) master and slave surfaces (Figure 3) are defined, where the slave surfaces are associated with the coarser mesh (backfill domain) which is typically connected to the adjacent finer mesh, representing a different (masonry) part of the bridge, by non-linear interfaces to model potential sliding and separation at the physical interface.

\section{Numerical examples}

The developed 3D modelling strategies with macro- and mesoscale masonry models are compared using ADAPTIC (Izzuddin, 1991), which is utilised to analyse the response up to collapse of a single-span masonry bridge previously tested in laboratory (Melbourne and Gilbert, 1995).

\subsection{Single-span masonry bridge}

The analysed single-span brick-masonry bridge specimen (Bridge 3-3, Figure 4) comprises a two-ring arch barrel with $3 \mathrm{~m}$ span, $215 \mathrm{~mm}$ thickness and 4:1 span-to-rise ratio. The arch is built according to the stretcher method in a segmental circular shape. The $330 \mathrm{~mm}$ thick spandrel walls are made of

Table 3. Macroscale material properties

$\begin{array}{lccccc}\boldsymbol{E}_{\mathrm{m}}: \mathbf{M P a} & \boldsymbol{v}_{\mathbf{m}} & \boldsymbol{\psi}_{\mathbf{m}} & \boldsymbol{f}_{\mathrm{tm}}: \mathbf{M P a} & \boldsymbol{G}_{\mathrm{tm}}: \mathbf{N} / \mathbf{m m} & \boldsymbol{f}_{\mathrm{cm}}: \mathbf{M P a} \\ 7200 & 0.15 & 0.61 & 0.20 & 0.02 & 25.9\end{array}$

English bond masonry. Full-size class A engineering bricks and a $1: 2: 9$ (cement:lime:sand) mortar are used for the brickwork, while the backfill filling the space above the arch and between the two lateral walls consists of $50 \mathrm{~mm}$ graded crushed limestone. In the experimental test, Bridge 3-3 specimen was subjected to a vertical centred patch load $\left(2600 \times 215 \mathrm{~mm}^{2}\right)$ increased up to collapse.

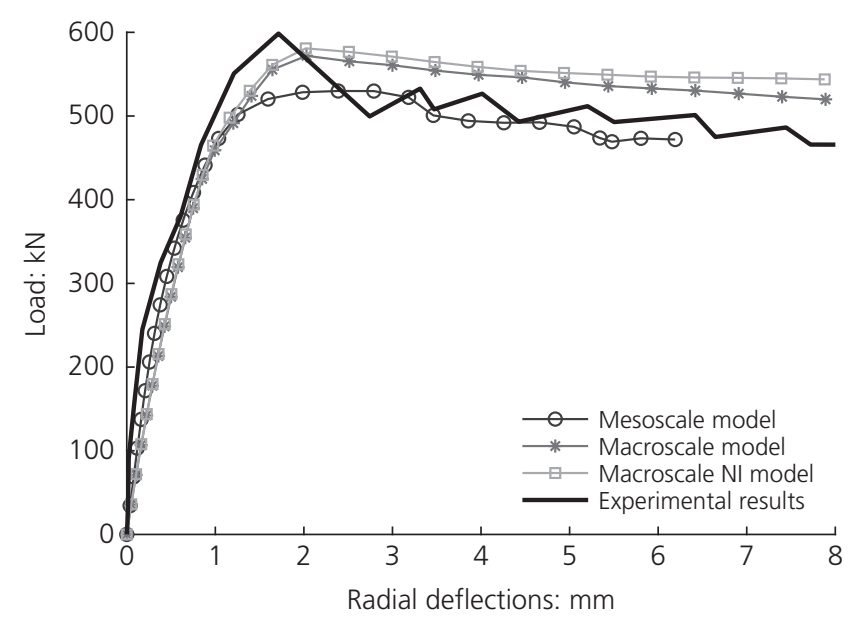

Figure 6. Load-displacement curves for meso and macroscale models 


\subsection{D meso- and macroscale models for the single-span masonry bridge}

The single-span bridge is modelled using macroscale and mesoscale models for masonry. The two FE meso- and macroscale descriptions are shown in Figure 5. The same mesh of solid elements is used to represent backfill in the two models, but the masonry components are modelled with different levels of discretisation. In the mesoscale, to allow for the actual bond in the brickwork, two solid elements per brick along the transverse direction are used for the arch and four solid elements per brick for the spandrel and wing walls. On the contrary, a coarser mesh of solid elements is employed for the masonry parts of the macroscale model. The number of elements and DOFs for the different components are reported in Table 1 for a total of 647679 DOFs for the mesoscale model and 45822 DOFs for the macroscale model. The same boundary

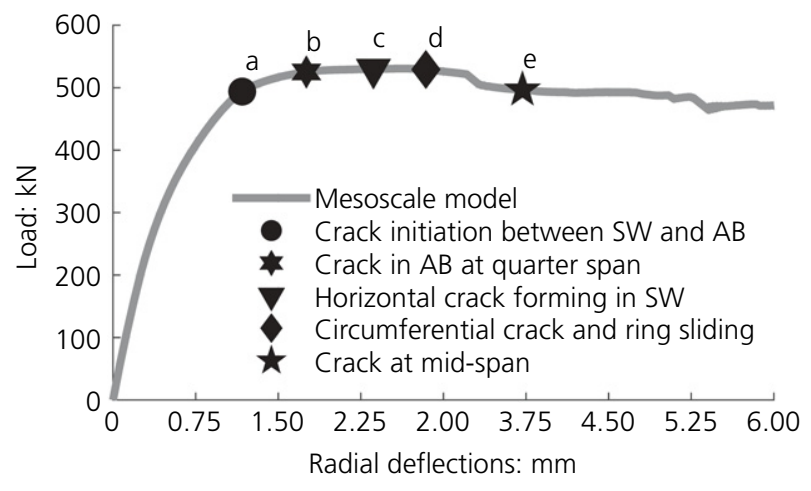

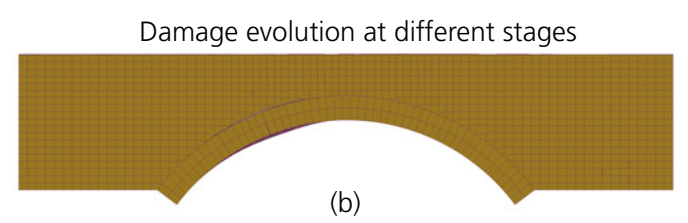

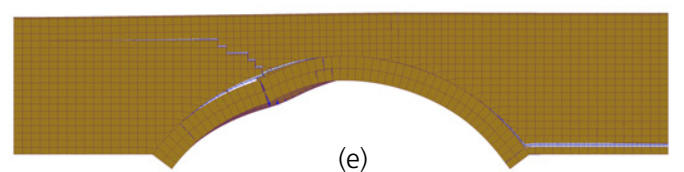

$\downarrow A$

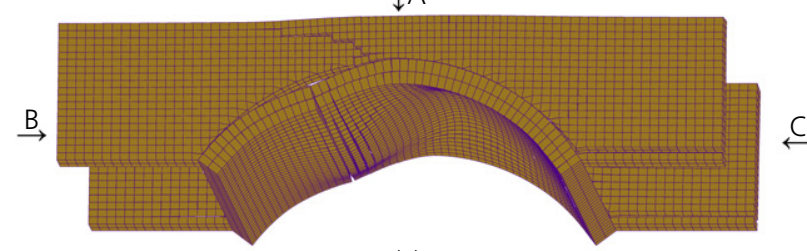

(e)
Evolution of plastic work in the masonry interfaces

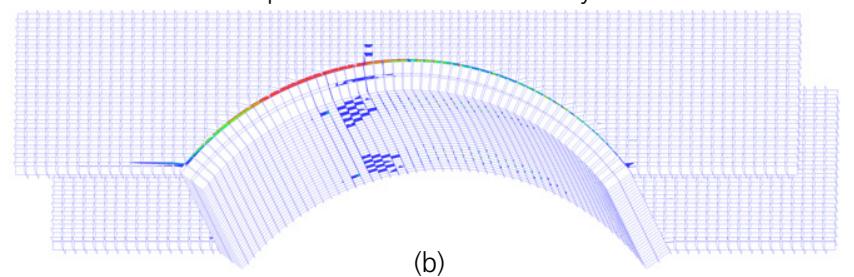

(b)

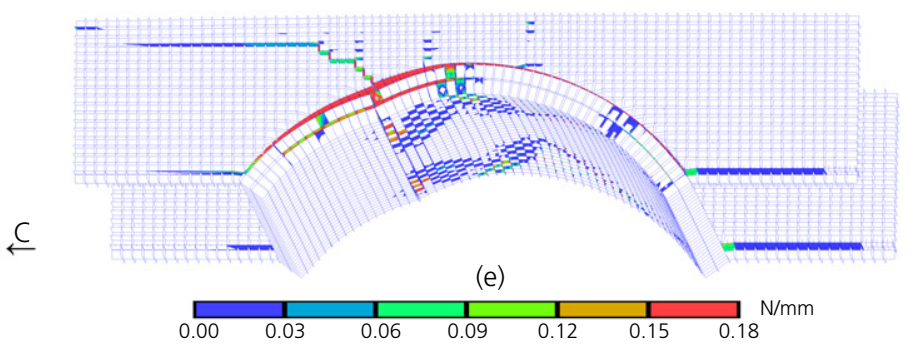

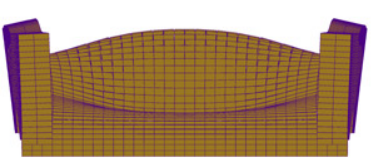

View: B

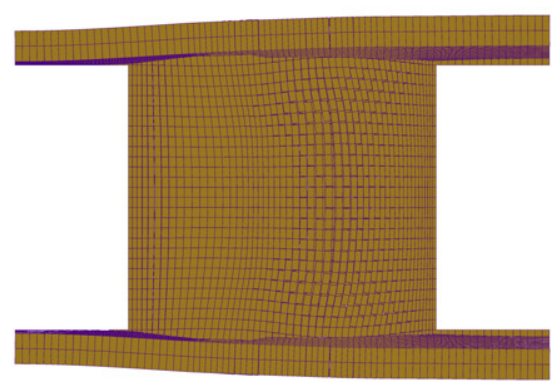

View: A

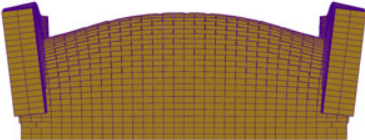

View: C

Figure 7. Cracks and damage (plastic work) predicted by the mesoscale model at different loading levels 
conditions are assumed for the two models with rigid supports at the base of the backfill and at the arch skewbacks, and horizontal support along the longitudinal direction at the two ends of backfill and lateral walls.

To improve computational efficiency, the partitioning strategy introduced before is adopted subdividing the two models into four partitions following the scheme shown in Figure 2.
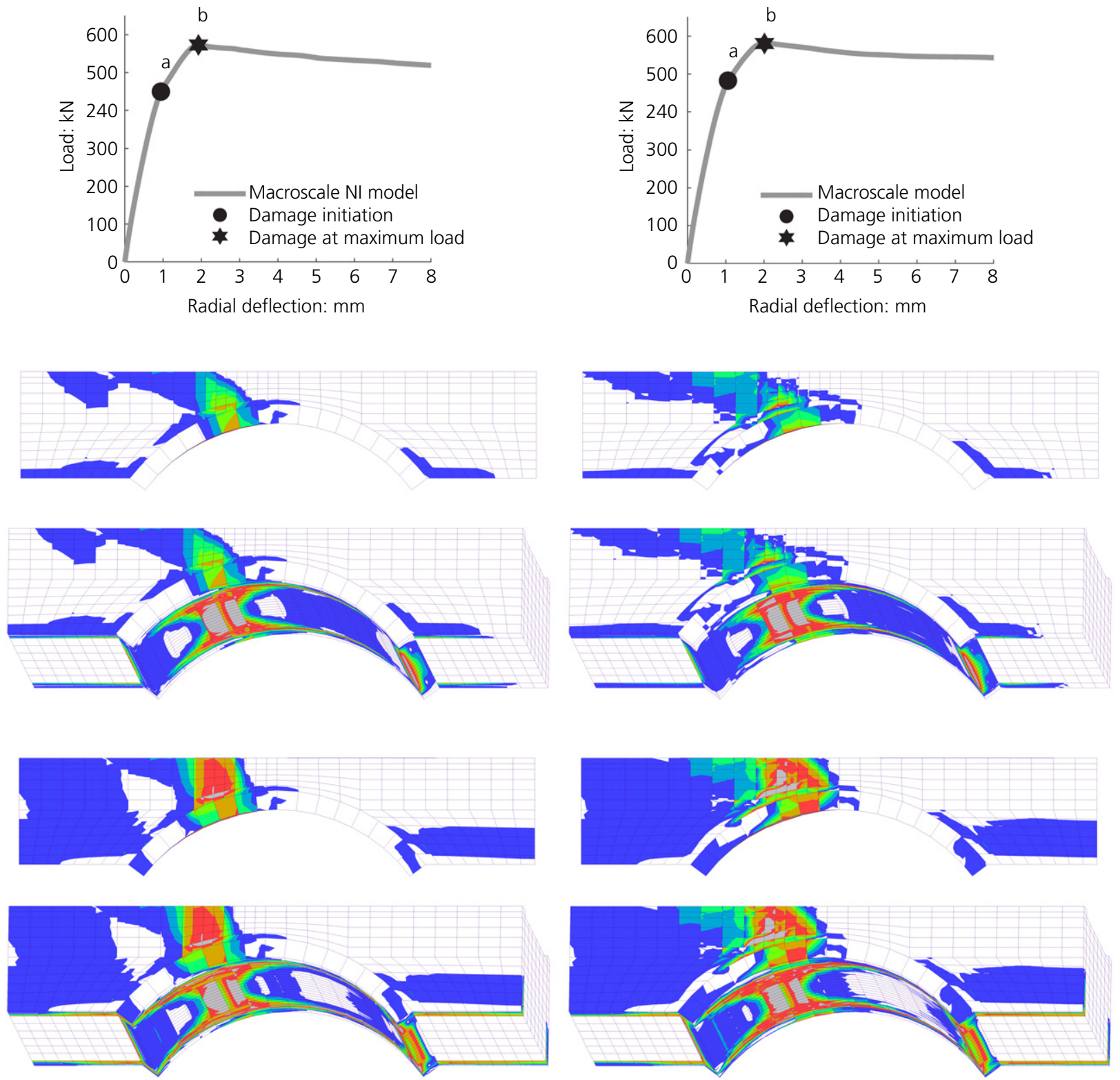

(a)
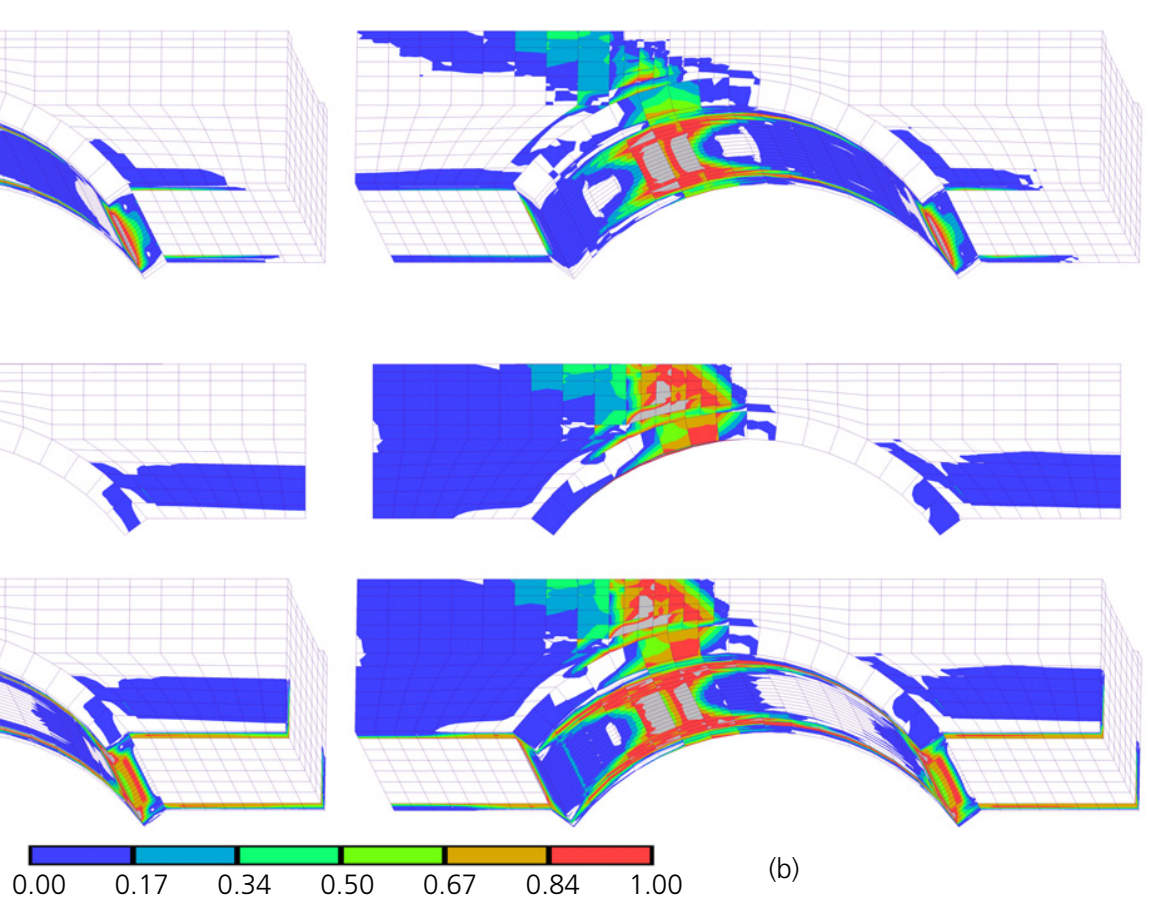
Poisson's ratio $v_{\mathrm{f}}=0.20$, cohesion $c_{\mathrm{f}}=0.001 \mathrm{MPa}$, friction angle $\varphi_{\mathrm{f}}=0.960$ and dilatancy angle $\psi_{\mathrm{f}}=0.436$, which correspond to the material parameters considered in previous research to describe crushed limestone (Zhang et al., 2018b). Concerning the material properties for masonry, the mesoscale material parameters recommended in Zhang et al. (2018b),
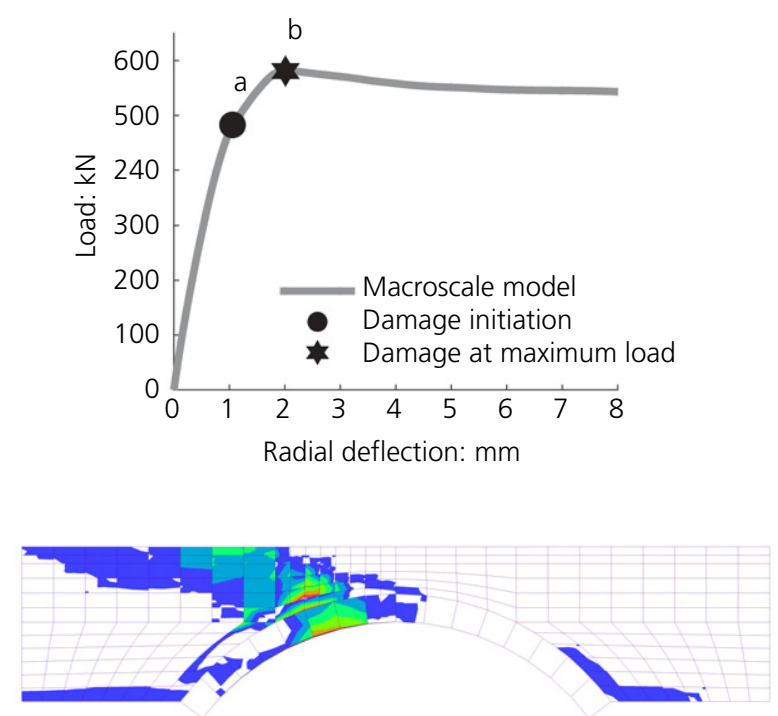

(b)

Figure 8. Cracks and damage (plastic work) predicted by the macroscale models at different loading levels 
Engineering and Computational Mechanics Volume 174 Issue 2
Numerical modelling of threedimensional masonry arch bridge structures

Grosman, Bilbao, Macorini and Izzuddin which also include properties from material tests (Melbourne and Gilbert, 1995), are utilised. More specifically, a Young's modulus $E_{\mathrm{b}}=16000 \mathrm{MPa}$ and a Poisson's ratio $v_{\mathrm{b}}=0.15$ are used for the elastic solid elements representing brick units, while the material properties reported in Table 2 are adopted

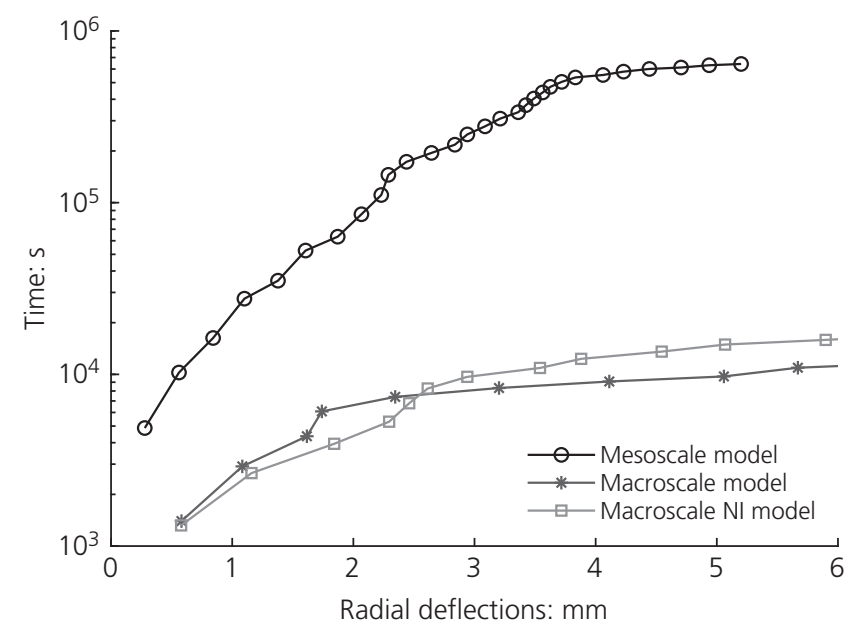

Figure 9. Computing time for meso and macroscale models

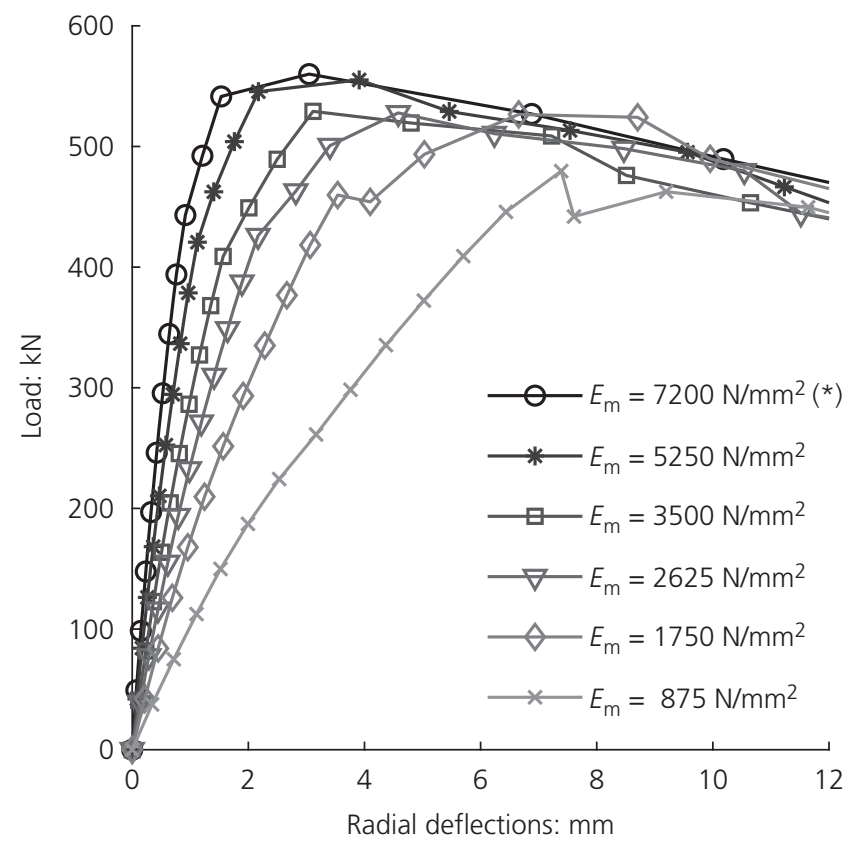

Figure 10. Macroscale load-displacement predictions for different values of Young's modulus for macroscale masonry - $\left({ }^{*}\right)$ reference curve

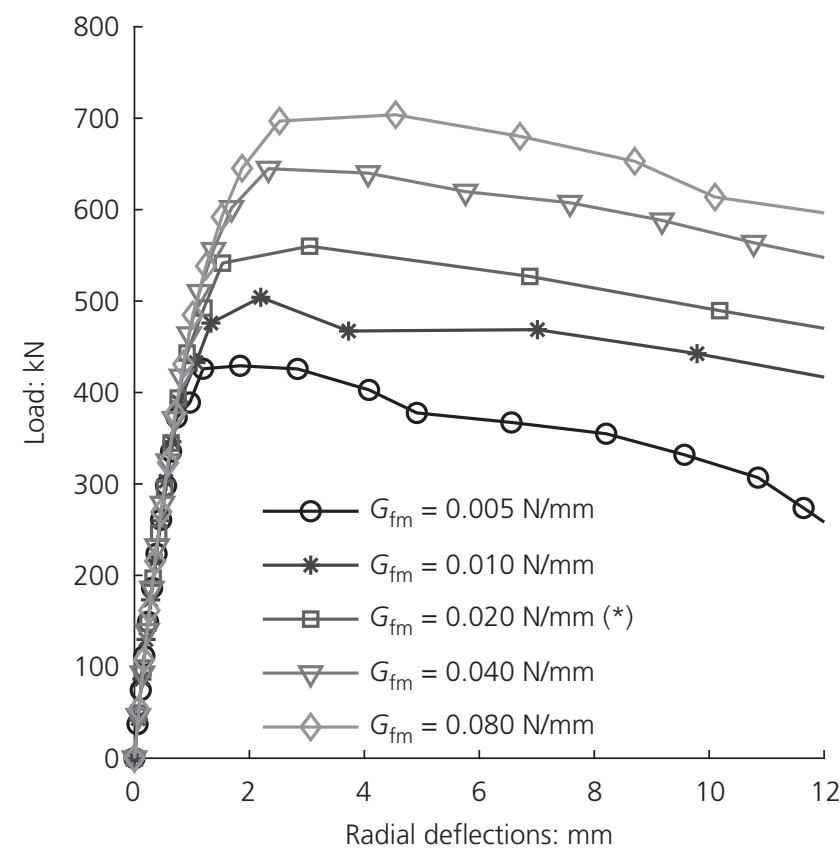

Figure 11. Macroscale load-displacement predictions for different values of fracture energy for macroscale masonry - $\left(^{*}\right)$ reference curve

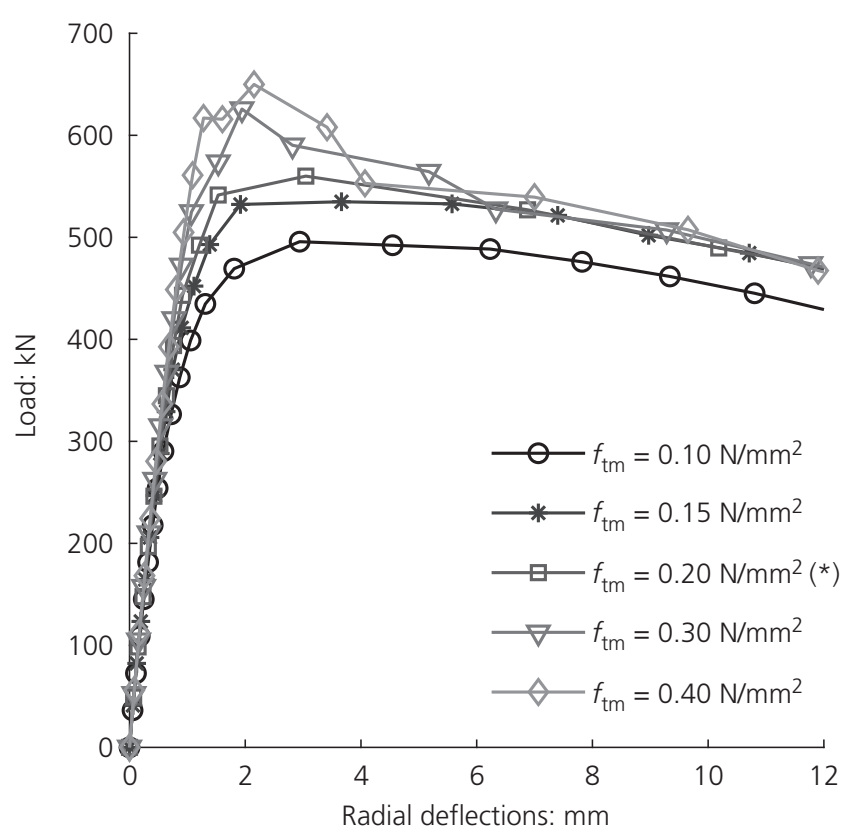

Figure 12. Macroscale load-displacement predictions for different values of tensile strength for macroscale masonry - $\left(^{*}\right)$ reference curve 
Table 4. Material properties for interface elements representing defective mortar joints

\begin{tabular}{cccccccccc}
$\boldsymbol{k}_{\mathrm{n}}: \mathbf{N} / \mathbf{m m}^{\mathbf{3}}$ & $\boldsymbol{k}_{\mathrm{t}}: \mathbf{N} / \mathbf{m m}^{\mathbf{3}}$ & $\boldsymbol{f}_{\mathrm{ti}}: \mathbf{M P a}$ & $\boldsymbol{f}_{\mathrm{ci}}: \mathbf{M P a}$ & $\boldsymbol{c : ~} \mathbf{M P a}$ & $\boldsymbol{G}_{\mathrm{ti}}: \mathbf{N} / \mathbf{m m}$ & $\boldsymbol{G}_{\mathrm{si}}: \mathbf{N} / \mathbf{m m}$ & $\boldsymbol{\varphi}_{\mathrm{i}}$ & $\boldsymbol{\psi}_{\mathrm{i}}$ \\
\hline 400 & 167 & 0.05 & 25.9 & 0.10 & 0.005 & 0.025 & 0.464 & 0.00
\end{tabular}

for the non-linear interface elements representing mortar joints and the physical interfaces between masonry and backfill. Finally, the material parameters used for the macroscopic masonry material model are indicated in Table 3. The macroscale masonry Young's modulus $E_{\mathrm{m}}$ has been determined considering the mesoscale elastic properties for bricks and mortar joints and a standard homogenisation procedure as in Pande et al. (1989), combining in-series the stiffness of bricks and mortar joints along the circumferential direction of the arch. Masonry macroscopic tensile strength $f_{\mathrm{tm}}$ is assumed as equal to the tensile strength of the interface elements for mortar joints anticipating that the non-linear response of the analysed structure is determined by the formation of radial cracks in the arch. Finally, the masonry macroscopic compressive strength $f_{\mathrm{cm}}$ corresponds to the value obtained in material tests conducted in parallel to the physical experiment on the bridge specimen (Melbourne and Gilbert, 1995).

\subsection{Model validation}

Numerical simulations are carried out to predict the response of the single-span masonry bridge up to collapse. Figure 6 shows a comparison between the experimental curve representing the variation of the radial displacements at the intrados of the arch barrel at quarter span against the applied load and three numerical curves. They have been obtained using the mesoscale and macroscale models described before, and an additional macroscale model with non-linear interfaces (Macroscale NI) to connect the different masonry parts and the backfill allowing for potential separation and sliding at the physical interfaces. In this case, 664 interface elements are used leading to a cumulative $61758 \mathrm{DOFs}$ for the Macroscale NI model which is $35 \%$ higher than the standard macroscale model.

The experimental numerical comparison indicates all three models slightly underestimate the initial stiffness of the bridge specimen. In addition, the two macroscale models provide an initial stiffness which is very close to the value determined by the more computationally expensive mesoscale model. This confirms the effectiveness of the basic homogenisation procedure to obtain masonry macroscale elastic parameters from mesoscale properties.

The mesoscale models provide an accurate prediction of the maximum load $(621 \mathrm{kN})$, which is in very good agreement with the maximum experimental load of $600 \mathrm{kN}$. In contrast, much higher maximum loads of 770 and $750 \mathrm{kN}$ are predicted by the macroscale model and the macroscale model with nonlinear interfaces, respectively. The use of non-linear interfaces to connect the different bridge components within a macroscale description only leads to a very marginal reduction of the maximum load prediction, but it influences the post peak response with a more pronounced softening behaviour.

Figure 7 shows the evolution of damage (plastic work associated with the tensile yield plane) and cracks in the brickwork determined by the mesoscale model. A radial crack in the arch barrel $(\mathrm{AB})$ underneath the applied load starts to develop at a load level of about $470 \mathrm{kN}$ and fully opens at $560 \mathrm{kN}$, when separation between arch and spandrel walls (SW) occur. For larger radial deflections, cracks at the mid-span of the arch form and the spandrel walls experience not negligible out-ofplane displacements. The predicted failure mechanism is close to that observed in the physical experiment, characterised by four large radial cracks in the arch and significant cracking also in the spandrel walls, confirming significant interaction between the different bridge components.

Figure 8 depicts the evolution of damage determined by the macroscale models. Also in this case, damage initiates in the arch at quarter span and then propagates in the lateral walls, but it is more confined around the loading area also at failure. Besides, the model with non-linear interfaces provides an improved prediction of the failure mechanism, as it enables separation between arch and spandrel walls, which

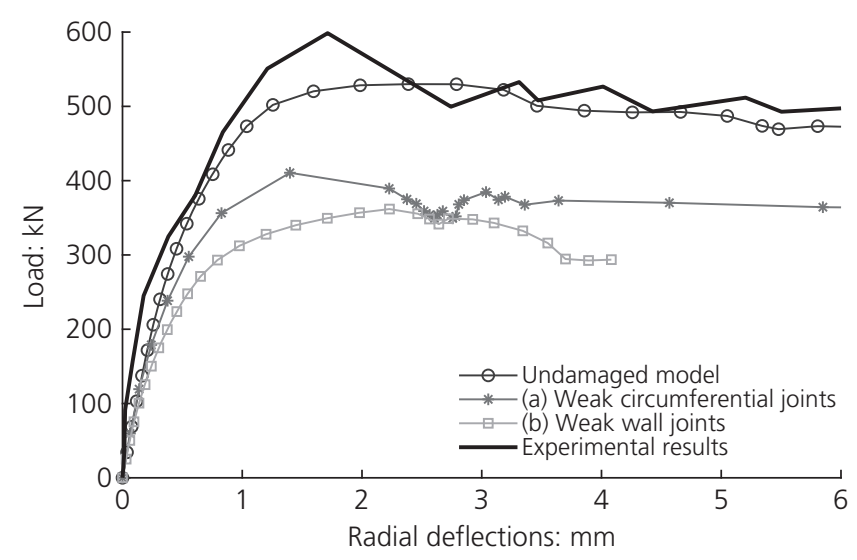

Figure 13. Load-displacement curves for mesoscale models with defected mortar joints 
facilitates the spreading of damage in the arch far from the applied load.

Figure 9 provides the computing times required by the different 3D models to reach different levels of radial displacements at the monitoring point on the arch (quarter span). This confirms the significantly higher cost required by mesoscale simulations and the improved efficiency of the two macroscale descriptions, which are characterised by a much-reduced number of DOFs compared to the mesoscale model (Table 1).

\subsection{Parametric study}

\subsubsection{Macroscale material parameters}

The results presented before indicate that $3 \mathrm{D}$ macroscale model would require a refined material calibration to potentially achieve an improved prediction of the bridge response up to collapse. In this regard, a multi-level calibration strategy, similar to the multi-scale approach employed in Chisari et al. (2020) to link mesoscale to macroscale masonry models for non-linear analysis of masonry wall structures, will be considered in future research for applications to masonry arches and bridges.

In order to identify the most critical masonry macroscale material properties, a parametric study is carried out. It has been found that masonry Young's modulus, tensile strength and fracture energy govern the bridge response at different loading levels. Masonry Young's modulus affects mostly the bridge stiffness, and it also determines the load-carrying capacity but not the post-peak response (Figure 10). On the other hand, as shown in Figure 11, masonry fracture energy in tension strongly determines the maximum load and the ductile (or brittle)
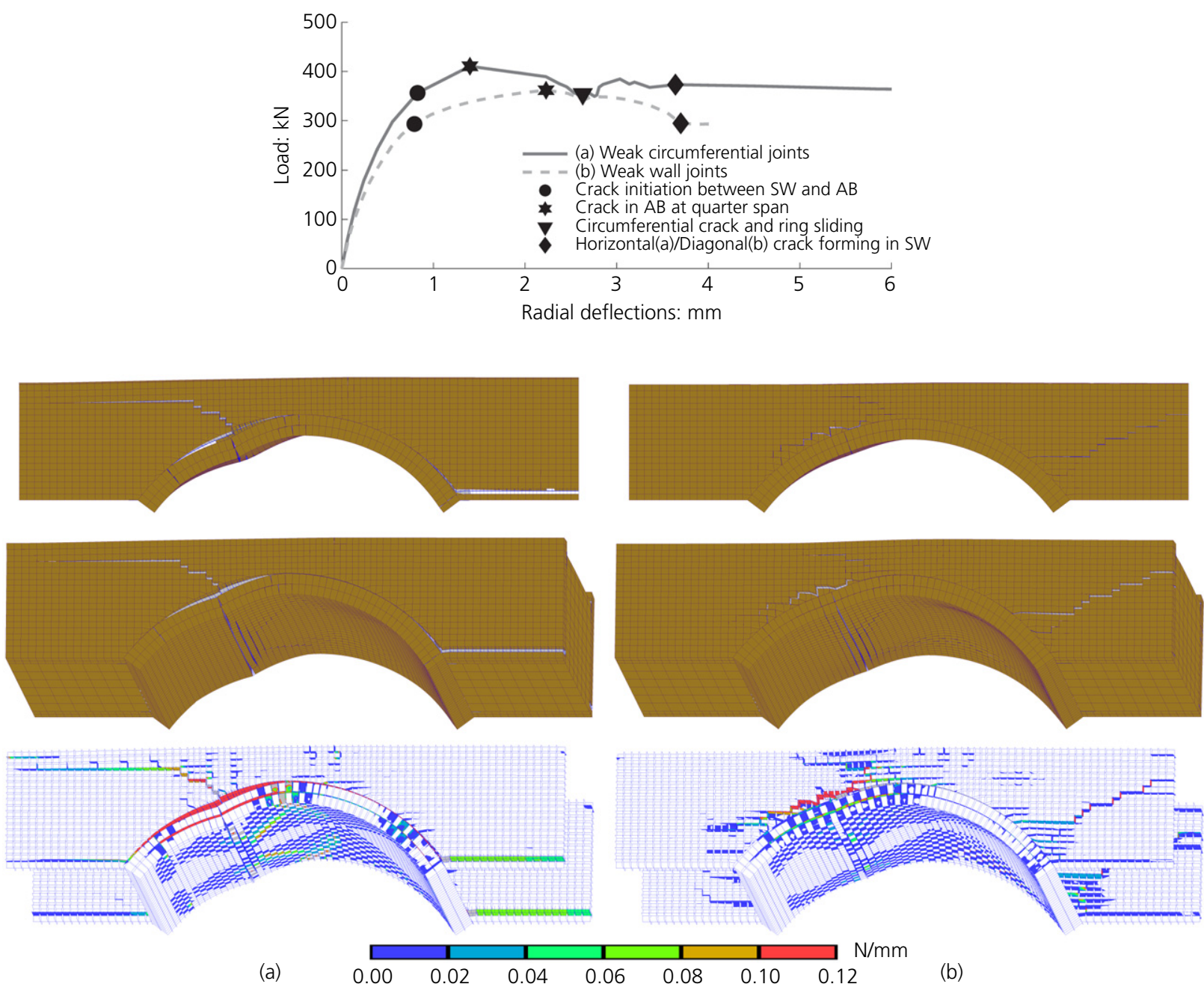

Figure 14. Cracks and damage (plastic work) predicted by the mesoscale model with (a) weak circumferential mortar joints in the arch, (b) with weak mortar joints in the lateral walls 


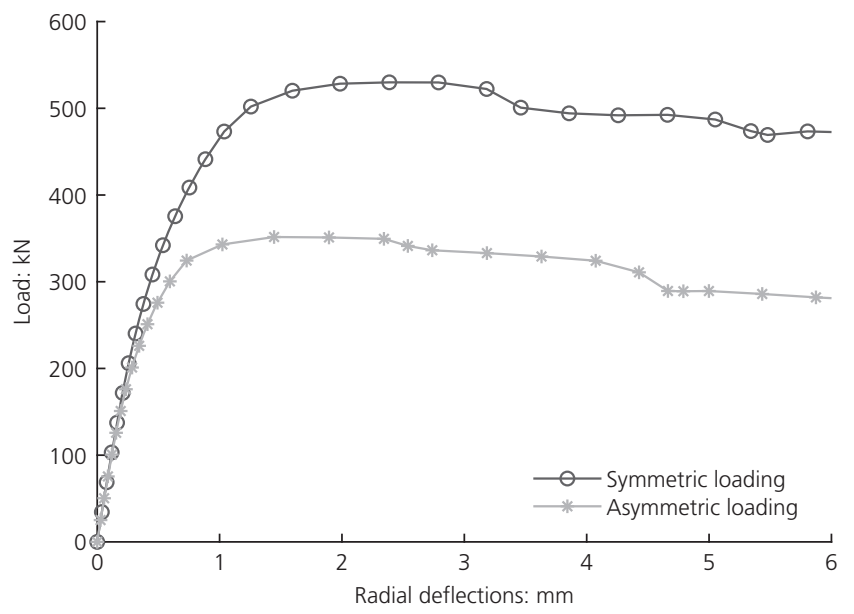

Figure 15. Load-displacement curves for mesoscale models with symmetric and asymmetric loading characteristics of the post-peak behaviour, but it does n't influence the behaviour at low loading levels. Finally, it was found that masonry tensile strength mainly governs the maximum load and the load when cracking initiates (Figure 12).

\subsubsection{Defects in the brickwork}

Alhough computationally expensive, detailed 3D mesoscale masonry models enable an accurate representation of the bridge response, as confirmed previously in the model validation study, as they explicitly allow for masonry bond. Thus, they can be used not only to calibrate more efficient models, but also to investigate the effects of specific defects in the brickwork which cannot be captured using conventional isotropic macroscale material models.

To show the potential of the proposed modelling strategy for masonry arch bridges, mesoscale simulations are conducted considering the effects of defective circumferential joints
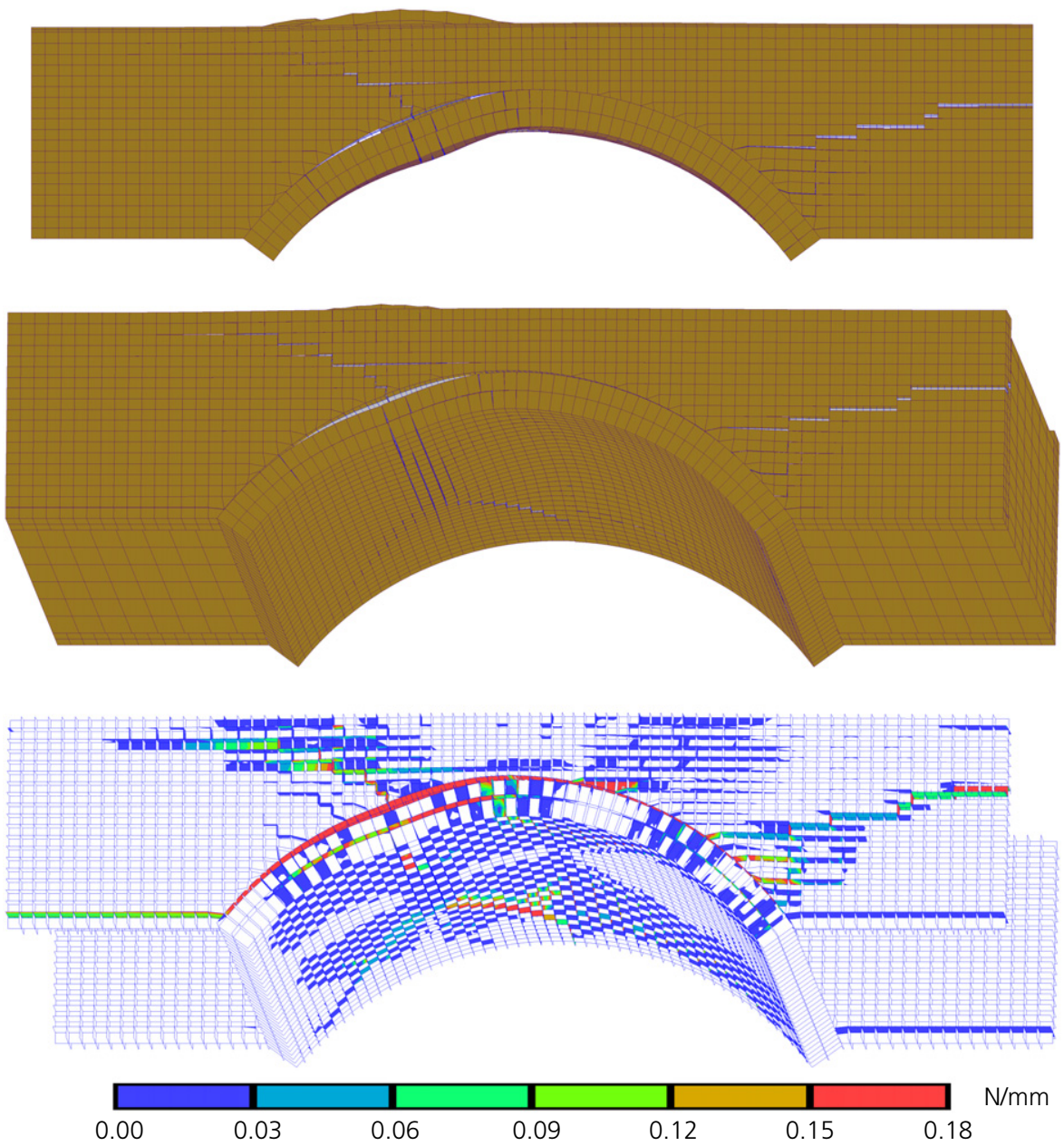

Figure 16. Cracks and damage (plastic work) predicted by the mesoscale model with asymmetric loading 
Engineering and Computational Mechanics Volume 174 Issue 2
Numerical modelling of three-

dimensional masonry arch bridge

structures

Grosman, Bilbao, Macorini and Izzuddin connecting the two rings of the brick masonry arch (weak circumferential joints) and the effects of degraded mortar joints in the lateral walls (weak wall joints). The material properties used to represent weak mortar joints in the two models are reported in Table 4.

The results obtained in the two simulations are compared against the numerical predictions for the reference mesoscale model with strong mortar joints in Figure 13. Both models with weak mortar joints predict a $15 \%$ decrease in load-carrying capacity. Importantly, weak circumferential joints in the arch induce early departure from the response of the structure with strong mortar joints which indicates an early damage and ring separation. On the other hand, the response of the model with defective spandrel walls practically coincides with that of the reference model almost up to reaching its maximum load.
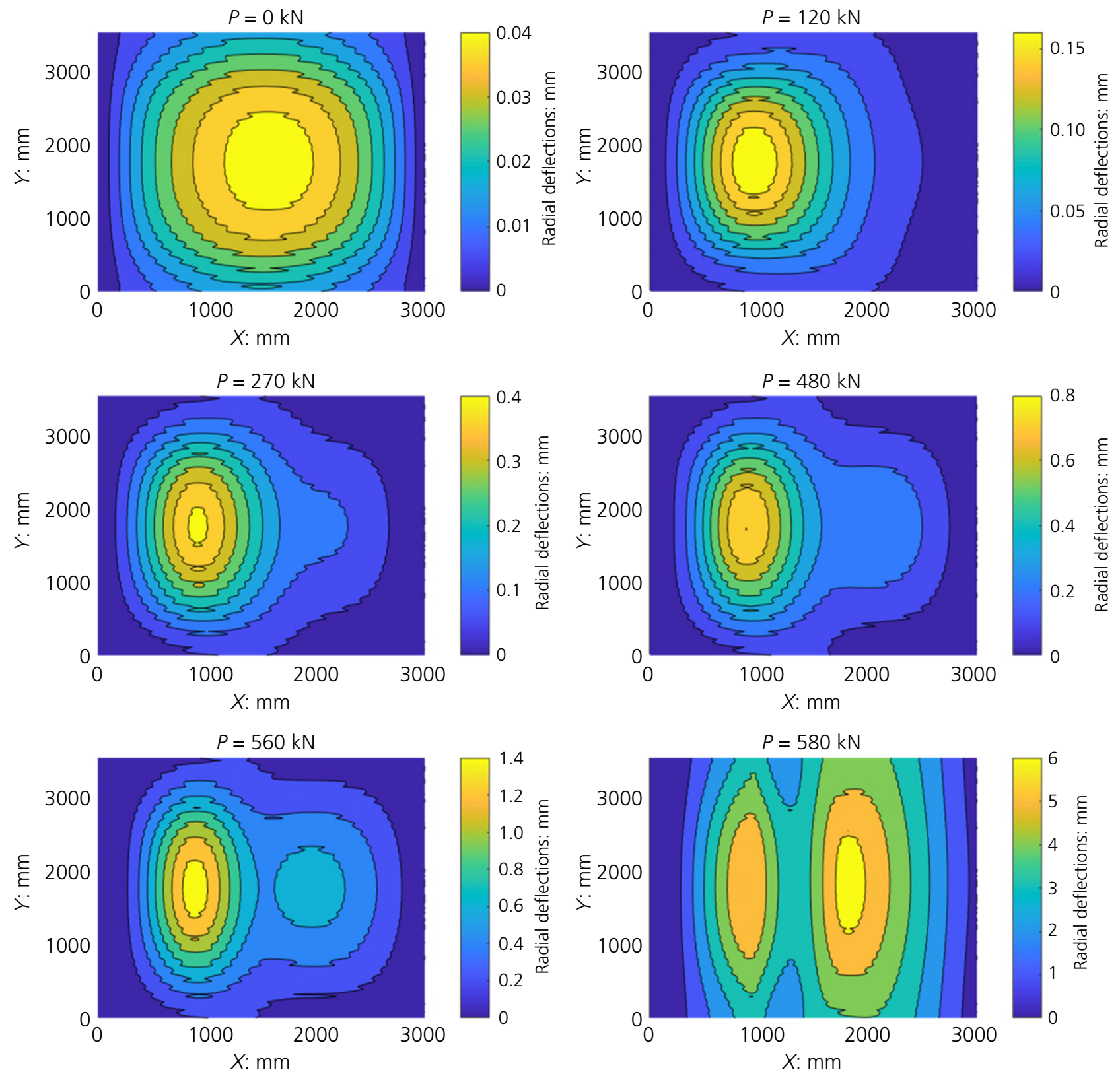

Symmetric loading

Figure 17. Iso-displacement maps at different loading levels determined by mesoscale model with symmetric loading 
Engineering and Computational Mechanics Volume 174 Issue 2
Numerical modelling of three-

dimensional masonry arch bridge

structures

Grosman, Bilbao, Macorini and Izzuddin
Figure 14 shows the failure mechanisms and damage in the interface elements (plastic work associated with the tensile yield plane) for the two models with weak mortar joints. Ring separation governs the ultimate response of the bridge model with weak circumferential joints hindering the development of cracking in the arch on the side opposite to where the load is applied. More significant damage in the spandrel walls developed in the model with weak joints which confirms the contribution of the lateral walls to the bridge resistance to vertical loading.
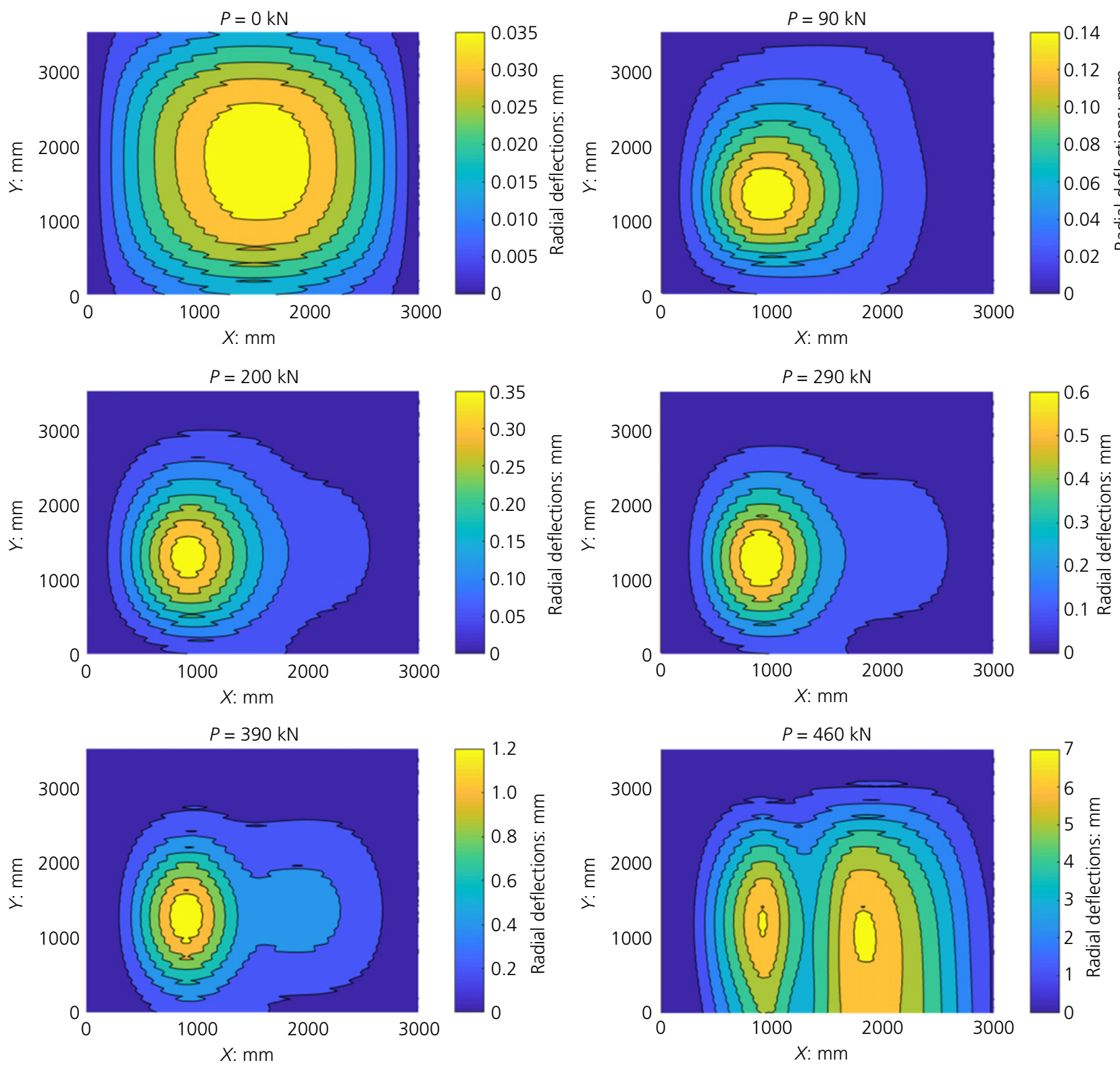

\subsubsection{Load eccentricity}

Additional mesoscale simulations are carried out to study the effect of load eccentricity. Most real masonry bridges are subjected to eccentric loading (e.g. train loads on multi-track railway bridges) and only the use of realistic $3 \mathrm{D}$ representations enables accurate predictions of the effect of such loading conditions on the bridge response at different load magnitudes. An initial investigation is conducted here by applying an asymmetric eccentric patch loading at quarter span with a patch length equal to half of that considered in the
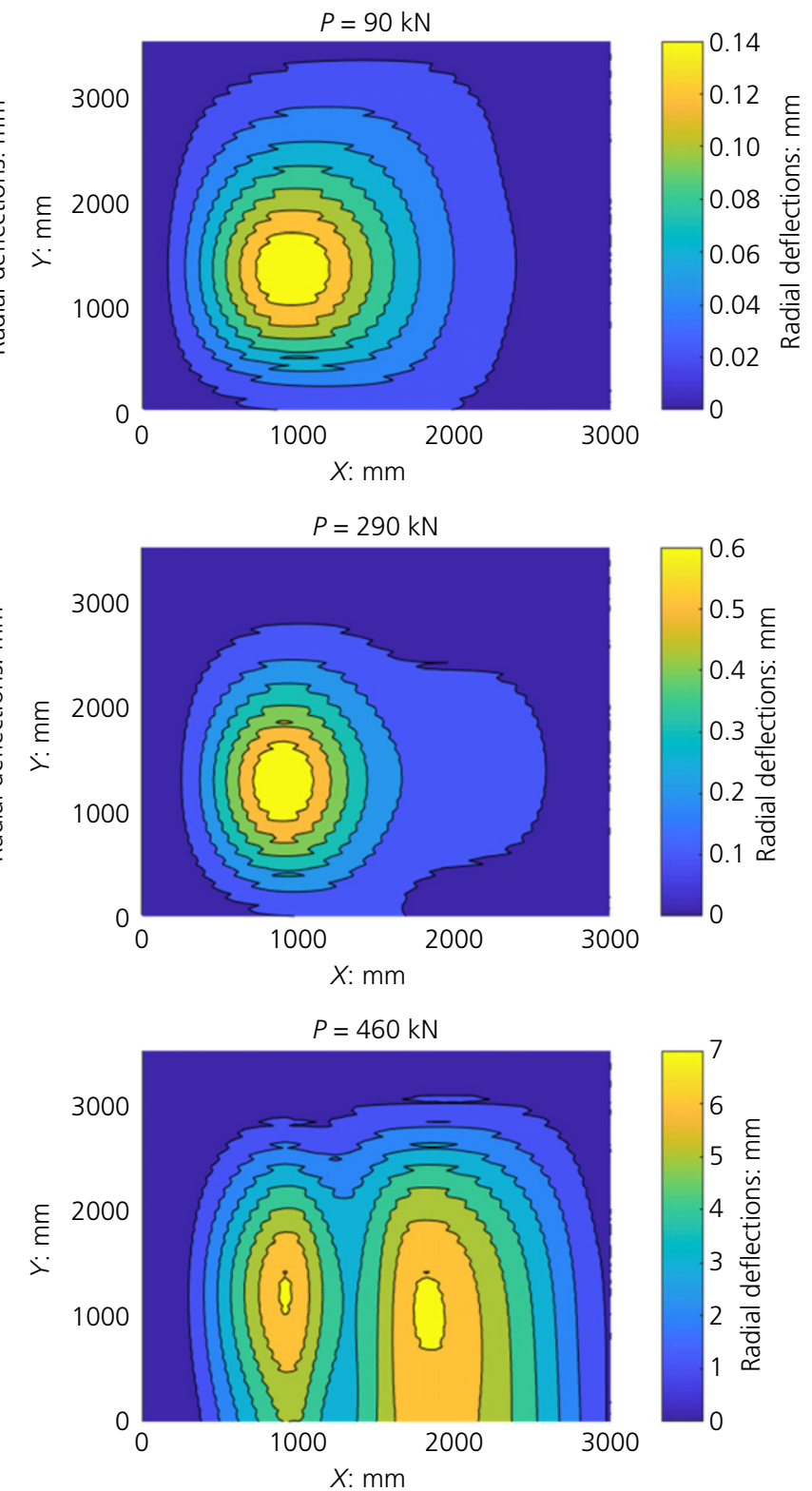

Asymmetric loading

Figure 18. Iso-displacement maps at different loading levels determined by mesoscale model with asymmetric loading 
base model. The predicted load-displacement response at quarter span is compared against the response obtained with the base model with symmetric loading in Figure 15, while the cracking pattern and tensile plastic work contours at failure for the asymmetric loading model are shown in Figure 16. A $35 \%$ decrease in the maximum load for eccentric loading is found. It is associated with a distinctive cracking pattern, which is different from that achieved for the specimen under symmetric loading, featuring extensive damage in the spandrel wall nearer to the loading area and in the arch underneath the applied load, where significant radial cracks form and develop into diagonal cracks towards the opposite site of the bridge as shown in Figure 16.

Finally, Figures 17 and 18 show the iso-displacement maps for the symmetric and asymmetric models, respectively. A strictly $3 \mathrm{D}$ response can be observed in the two cases, where the eccentricity of loading leads to greater displacements at the lateral wall in the proximity of the loaded area which reflects the high damage in this bridge component.

\section{Conclusions}

This paper investigates the use of two detailed 3D modelling approaches recently developed at Imperial College, namely mesoscale and macroscale modelling approaches, to study the response of a single-span masonry arch bridge at different loading levels up to failure.

Macroscale models are shown to be capable of predicting the main features of the inherent $3 \mathrm{D}$ response including location, initiation and propagation of damage reasonably, albeit at the cost of simplifying masonry to a homogeneous material, hence missing some local effects such as the influence of masonry bond. This may lead to inaccurate prediction of the maximum load-carrying capacity which calls for refined calibration of macroscale model parameters.

The use of non-linear interface elements to represent the physical interfaces between distinct bridge components leads to improved predictions especially regarding failure modes with significant damage in different sections of the arch which is facilitated by the separation from the lateral walls.

Mesoscale models, though more sophisticated and computationally demanding, are capable of capturing local damage phenomena by accounting for different material properties in the various constituents, including for example ring separation.

Within the boundaries of serviceability, the discrepancy between the two modelling approaches is not significantly accentuated. This indicates that the macroscale model type can be used for assessment purposes under traffic loading in service, although mesoscale models can still play a significant role in the investigation of realistic failure mechanisms, in the calibration of the more efficient macroscale models and in the modelling of specific structural subdomains where further insight is needed.

It is important to note that the increase in method complexity also requires an increase in the accuracy of a greater set of input parameters, which may not be readily available. Consequently, more sophisticated and computationally demanding methods do not automatically imply better results if the conditions for their suitability are not met. In general, the optimal choice of assessment method depends on a number of factors including, among others, the available information with regards to material properties, the computational resources and the desired level of accuracy.

Finally, the results obtained confirm the strictly 3D nature of the bridge response which cannot be captured by the standard $2 \mathrm{D}$ representations currently used in assessment practice. This implies the need for developing enhanced assessment tools, which could most effectively be calibrated based on the results provided by advanced 3D computational models, such as those presented in this paper.

Further research will focus on developing more advanced calibrations strategies for standard macroscale material descriptions and more refined macroscale models capable of representing different cracking patterns associated with masonry bond, including separation between adjacent rings of multi-ring arches. Investigation of realistic masonry bridges and viaducts will also be considered in future research, where the effects of material degradation, defects, existing cracking on the response under traffic loading in service and at failure will be studied.

\section{Acknowledgements}

The support of the HPC Services at Imperial College London is gratefully acknowledged by the authors.

\section{REFERENCES}

Audenaert A, Fanning P, Sobczak L and Peremans H (2008) 2-D analysis of arch bridges using an elasto-plastic material model. Engineering Structures 30(3): 845-855.

Augusthus-Nelson L, Swift G, Melbourne C, Smith C and Gilbert M (2018) Large-scale physical modelling of soil-filled masonry arch bridges. International Journal of Physical Modelling in Geotechnics 18(2): 81-94.

Brencich A and De Francesco U (2004) Assessment of multispan masonry arch bridges. I: simplified approach. Journal of Bridge Engineering 9(6): 582-590.

Caddemi S, Calió I, Cannizzaro F et al. (2019) 3D discrete macro modelling approach for masonry arch bridges. IABSE Symposium: Towards a Resilient Built Environment Risk and Asset 
Management, Guimaraes, Portugal. International Association for Bridge and Structural Engineering (IABSE), Zurich, Switzerland, pp. $1825-1835$.

Callaway P, Gilbert M and Smith CC (2012) Influence of backfill on the capacity of masonry arch bridges. Proceedings of the Institution of Civil Engineers: Bridge Engineering 165(3): 147-157.

Cavicchi A and Gambarotta L (2007) Lower bound limit analysis of masonry bridges including arch-fill interaction. Engineering Structures 29(11): 3002-3014

Chandra Kishen JM, Ramaswamy A and Manohar CS (2013) Safety assessment of a masonry arch bridge: field testing and simulations. Journal of Bridge Engineering 18(2): 162-171.

Chisari C, Macorini L, Amadio C and Izzuddin BA (2018) Identification of mesoscale model parameters for brick-masonry. International Journal of Solids and Structures 146: 224-240.

Chisari C, Macorini L and Izzuddin BA (2020) Multiscale model calibration by inverse analysis for nonlinear simulation of masonry structures under earthquake loading. International Journal for Multiscale Computational Engineering 18(2): 241-263.

Choo BS, Coutie MG and Gong NG (1990) The application of the finite element method to the study of cracking in masonry arch bridges. In Applied Stress Analysis (Hyde TH and Ollerton E (eds.)). Springer Netherlands, Dordrecht, the Netherlands.

Crisfield MA (1985) Finite Element and Mechanism Methods for the Analysis of Masonry and Brickwork Arches. TRRL, Crowthorne, UK.

Crisfield MA and Packham AJ (1987) A Mechanism Program for Computing the Strength of Masonry Arch Bridges. Transport Research Laboratory, Crowthorne, UK.

CUR (1994) Structural Masonry: an Experimental/Numerical Basis for Practical Design Rules. CUR, Gouda, The Netherlands, Report 171.

De Santis S and De Felice G (2014) A fibre beam-based approach for the evaluation of the seismic capacity of masonry arches. Earthquake Engineering \& Structural Dynamics 43(11): 1661-1681.

Fanning PJ, Boothby TE and Roberts BJ (2001) Longitudinal and transverse effects in masonry arch assessment. Construction and Building Materials 15(1): 51-60.

Forgács T, Sarhosis V and Bagi K (2017) Minimum thickness of semi-circular skewed masonry arches. Engineering Structures 140: $317-336$

Gago AS, Alfaiate J and Lamas A (2011) The effect of the infill in arched structures: analytical and numerical modelling. Engineering Structures 33(5): 1450-1458.

Garrity SW and Toropova IL (2001) A finite element study of a single span masonry arch bridge with near surface reinforcement. ARCH'01 - 3me conférence sur les ponts en arc, Paris, France (Abdunur C (ed.)). Presses de l'Ecole nationale des ponts et chaussées, Paris, France, pp. 567-572.

Gilbert M and Melbourne C (1994) Rigid-block analysis of masonry structures. The Structural Engineer 72(21): 356-361.

Gilbert M, Smith C, Melbourne C and Wang J (2006) An experimental study of soil-arch interaction in masonry bridges. In Advances in Bridge Maintenance, Safety Management, and Life-Cycle Performance (da Sousa Cruz PJ, Frangopol DM and Canhoto Neves LC (eds)). CRC Press, London, UK, pp. 778-780.

Hart R, Cundall PA and Lemos J (1988) Formulation of a threedimensional distinct element model - Part II. Mechanical calculations for motion and interaction of a system composed of many polyhedral blocks. International Journal of Rock
Mechanics and Mining Sciences \& Geomechanics Abstracts 25(3): $117-125$.

Heyman J (1982) The Masonry Arch. Cambridge University Press, Cambridge, UK.

Izzuddin BA (1991) Nonlinear Dynamic Analysis of Framed Structures. $\mathrm{PhD}$, Imperial College London, London, UK

Izzuddin BA and Jokhio GA (2017) Mixed-dimensional coupling for parallel partitioned nonlinear finite-element analysis. Journal of Computing in Civil Engineering, ASCE 31(3): 04016062 .

Jokhio GA and Izzuddin BA (2015) A dual super-element domain decomposition approach for parallel nonlinear finite element analysis. International Journal for Computational Methods in Engineering Science and Mechanics 16(3): 188-212.

Lee J and Fenves G (1998) Plastic-damage model for cyclic loading of concrete structures. Journal of Engineering Mechanics 124(8): 892-900

Livesley RK (1978) Limit analysis of structures formed from rigid blocks. International Journal for Numerical Methods in Engineering 12: $1853-1871$.

Macorini L and Izzuddin BA (2011) A non-linear interface element for 3D mesoscale analysis of brick-masonry structures. International Journal for Numerical Methods in Engineering 85(12): 1584-1608.

Macorini L and Izzuddin BA (2013) Nonlinear analysis of masonry structures using mesoscale partitioned modelling. Advances in Engineering Software 60: 58-69.

Melbourne C and Gilbert M (1995) Behaviour of multiring brickwork arch bridges. The Structural Engineer 73(3): 39-47.

Melbourne C and Walker P (1990) Load Test to Collapse on a Full-Scale Model Six Metre Span Brick Arch Bridge. Transport and Road Research Laboratory, London, UK.

Melbourne C, Gilbert M and Wagstaff M (1997) The collapse behaviour of multi span brickwork arch bridges. The Structural Engineer 75(17): 297-305.

Milani G and Lourenço PB (2012) 3D non-linear behavior of masonry arch bridges. Computers and Structures 110-111: 133-150

Minga E, Macorini L and Izzuddin BA (2018a) A 3D mesoscale damage-plasticity approach for masonry structures under cyclic loading. Meccanica 53(7): 1591-1611.

Minga E, Macorini L and Izzuddin BA (2018b) Enhanced mesoscale partitioned modelling of heterogeneous masonry structures. International Journal for Numerical Methods in Engineering 113(13): 1950-1971.

Page J (1995) Load tests to collapse on masonry arch bridges. In Arch Bridges. Thomas Telford Publishing, London, UK, pp. 289-298, https://doi.org/10.1680/ab.20481.0029.

Pande GN, Liang JX and Middleton J (1989) Equivalent elastic moduli for brick masonry. Computers and Geotechnics 8(3): 243-265.

Peng D, Fairfield C and Sibbald A (1997) Experimental validation of flat arch analysis techniques. Proceedings of the 7th International Conference on Structural Faults and Repairs, Edinburgh, UK. Engineering Technics Press, Edinburgh, UK.

Pippard AJS (1948) The approximate estimation of safe loads on masonry bridges. In The Civil Engineer in War. Thomas Telford Ltd, London, UK, pp. 365-372.

Pippard AJS and Chitty L (1951) A Study of the Voussoir Arch. HMSO, London, UK.

Pulatsu B, Erdogmus E and Lourenço PB (2019) Simulation of masonry arch bridges using 3D discrete element modeling. In Structural Analysis of Historical Constructions (Aguilar R, Torrealva D, Moreira S, Pando MA and Ramos LF (eds)). RILEM Bookseries, vol. 18 , pp. $871-880$. 
Thavalingam A, Bicanic N, Robinson JI and Ponniah DA (2001) Computational framework for discontinuous modelling of masonry arch bridges. Computers \& Structures 79(19): 1821-1830.

Towler WJ and Sawko F (1982) Limit state behaviour of brickwork arches. Proceedings of the 6th International Conference on Brick Masonry, Rome, Italy.

Tubaldi E, Macorini L and Izzuddin BA (2018) Three-dimensional mesoscale modelling of multi-span masonry arch bridges subjected to scour. Engineering Structures 165: 486-500.

Tubaldi E, Macorini L and Izzuddin BA (2020a) Identification of critical mechanical parameters for advanced analysis of masonry arch bridges. Structure and Infrastructure Engineering 169(2): $328-345$
Tubaldi E, Minga E, Macorini L and Izzuddin BA (2020b) Mesoscale analysis of multi-span masonry arch bridges. Engineering Structures 225: 1-16.

Zhang Y, Macorini L and Izzuddin BA (2016) Mesoscale partitioned analysis of brick-masonry arches. Engineering Structures 124: $142-166$.

Zhang Y, Macorini L and Izzuddin BA (2018a) Numerical investigation of arches in brick-masonry bridges, Structure and Infrastructure Engineering 14(1): 14-32.

Zhang Y, Tubaldi E, Macorini L and Izzuddin BA (2018b) Mesoscale partitioned modelling of masonry bridges allowing for arch-backfill interaction. Construction and Building Materials 173: $820-842$.

\section{How can you contribute?}

To discuss this paper, please email up to 500 words to the editor at journals@ice.org.uk. Your contribution will be forwarded to the author(s) for a reply and, if considered appropriate by the editorial board, it will be published as discussion in a future issue of the journal.

Proceedings journals rely entirely on contributions from the civil engineering profession (and allied disciplines).

Information about how to submit your paper online is available at www.icevirtuallibrary.com/page/authors, where you will also find detailed author guidelines. 